Special Issue of the 8th International Advances in Applied Physics and Materials Science Congress (APMAS 2018)

\title{
Microwave Assisted Hydroxyapatite Coating of Ti6Al4V Alloys and Investigation of Adhesion Strength
}

\author{
Ş. AVCI ${ }^{a, *}$ AND Y.E. ŞIMŞEK ${ }^{b}$ \\ ${ }^{a}$ Bilecik Şeyh Edebali University, Department of Materials Science and Engineering, Bilecik, Turkey \\ ${ }^{b}$ Bilecik Şeyh Edebali University, Department of Chemical Engineering, Bilecik, Turkey
}

\begin{abstract}
The coating of biocompatible materials enables the integration of bone and metal implant more effectively. Calcium phosphate substances with a suitable ratio of $\mathrm{Ca} / \mathrm{P}$ are bioactive, biocompatible, and osteoconductive and enhance direct attachment to bone. To that end, to boost the bioactivity of titanium alloys, uniform hydroxyapatite coatings were prepared on Ti6Al4V titanium alloy substrates using microwave-assisted immersion method. The effect of the number of cycle i.e. exposure time to a constant microwave irradiation power of $800 \mathrm{~W}$ on the coating thickness, surface morphology and adhesion strength was thoroughly investigated. The homogeneity of the coating increased as the number of cycles was increased. Also, the adhesion strength of coatings was measured by mechanical tests.
\end{abstract}

DOI: 10.12693/APhysPolA.135.972

PACS/topics: biomaterials, hydroxyapatite, Ti6Al4V, coating, microwave

\section{Introduction}

Because of their lack of bioactivity, biometals cannot bond with the bone and do not promote new bone cell growth on the implant surface $[1,2]$. Biometals can be coated with bioactive materials to improve their biocompatibility and enhance the bone growth [3, 4]. Hydroxyapatite (HAP) has chemical and structural similarities with inorganic part of the human hard tissue, thus, HAP is biocompatible and bioactive and it can be rapidly integrated into the human body $[5,6]$. However, bulk HAP cannot be used for load bearing applications because of its low mechanical properties [7]. The best way to overcome low mechanical properties of hydroxyapatite is to coat it on metal substrates $[4,8,9]$. The metallic materials may be coated with HAP using simulated body fluid (SBF) [9]. Microwave assisted methods are often used because of their advantages such as fast, efficient and homogeneous processes [3]. The aim of this study is to coat Ti6Al4V alloys with HAP in 10XSBF using microwave irradiation technique and to investigate the adhesion strength of the coatings. Ti6Al4V alloys were coated with different cycles $(1,2,3,4,5)$ of $3 \mathrm{~min}$ each, using $800 \mathrm{~W}$ microwave irradiation of a domestic microwave oven. Following the coating process, the physical, mechanical, and morphological properties of the coating were investigated by SEM, XRD, FTIR, optical microscopy, and tensile test.

\section{Experimental procedure}

Ti6Al4V alloys (Grade 5, ASTM B265) with dimensions of $10 \mathrm{~mm}$ in diameter and $20 \mathrm{~mm}$ in length were

*corresponding author; e-mail: senol.avci@bilecik.edu.tr abraded manually with $1200 \mathrm{SiC}$ paper. Abraded samples were ultrasonically cleaned in acetone, ethanol and ultrapure water, respectively, for 15 minutes for each step. Thereafter, all the samples were etched with $2 \mathrm{ml} \mathrm{HF} \mathrm{(40 \% )} \mathrm{and} 4 \mathrm{ml} \mathrm{HNO}_{3}(60 \%)$ solution in an ultrasonic bath for $10 \mathrm{~min}$. Etched specimens were again cleaned in an ultrasonic bath with ultrapure water for $15 \mathrm{~min}$. To prepare the HAP coating solution the reagents, $\mathrm{NaCl}\left(58.443 \mathrm{~g}, \mathrm{KCl}(0.373 \mathrm{~g}), \mathrm{CaCl}_{2}\right.$. $2 \mathrm{H}_{2} \mathrm{O}(3.675 \mathrm{~g}), \mathrm{MgCl}_{2} \cdot 6 \mathrm{H}_{2} \mathrm{O}(1.016 \mathrm{~g}), \mathrm{NaH}_{2} \mathrm{PO}_{4} \cdot \mathrm{H}_{2} \mathrm{O}$ $(0.250 \mathrm{~g})$, were dissolved successively, using a magnetic stirrer in $900 \mathrm{~mL}$ ultrapure water at room temperature. After all chemicals dissolved, $100 \mathrm{~mL}$ of ultrapure water was added to the solution. For HAP coating, $0.84 \mathrm{~g}$ of $\mathrm{NaHCO}_{3}$ was added to an aliquot solution of $200 \mathrm{~mL}$ from the stock solution and the resultant solution was stirred vigorously. For the first cycle, as soon as $\mathrm{NaHCO}_{3}$ was dissolved completely, Ti6Al4V specimens were put in the solution and the beaker was placed into a domestic microwave oven and was exposed to $800 \mathrm{~W}$ of irradiation for $3 \mathrm{~min}$. The samples were subjected to 5 different cycles. After the coating procedures were completed, the samples were taken out of the solutions, rinsed with ultrapure water, and dried in the open air. Coated Ti6Al4V samples were characterized using SEM, XRD, and FTIR. Coating thicknesses were measured by optical microscope. To determine the bonding strength of coatings, samples were attached with glue to a cylindrical stainless steel bar, $10 \mathrm{~mm}$ in diameter and $20 \mathrm{~mm}$ in length. Tensile load was applied to the samples with a Precision Universal Tester at a crosshead speed of $1 \mathrm{~mm} / \mathrm{min}$ until fracture occurred.

\section{Results and discussion}

The SEM photos, shown in Fig. 1a, b, depict the change in the surface morphology of the HAP coated sample in different cycle numbers. As the number of 
cycles was increased, it was observed by SEM that the alloy surface was coated more uniformly. This uniformity was also supported by optical image. As seen from the Fig. 1c, the average thickness of the coating was measured as $23.81 \mu \mathrm{m}$.
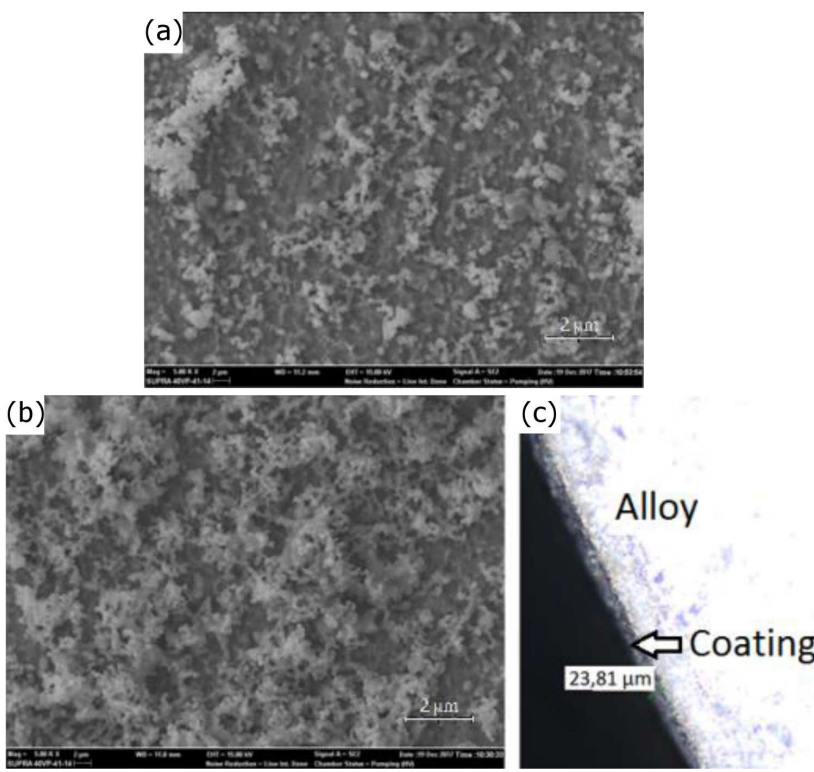

Fig. 1. SEM micrographs of (a) cycle 3, (b) cycle 5, and (c) optical image of HAP coatings.
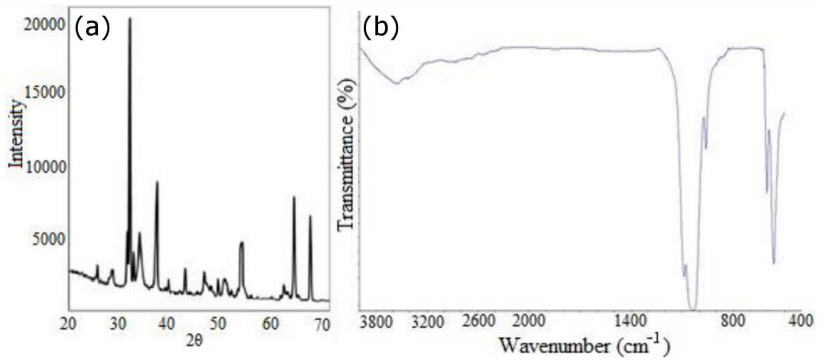

Fig. 2. (a) X-ray diffraction pattern and (b) FTIR spectra of HAP coating for cycle 5 .

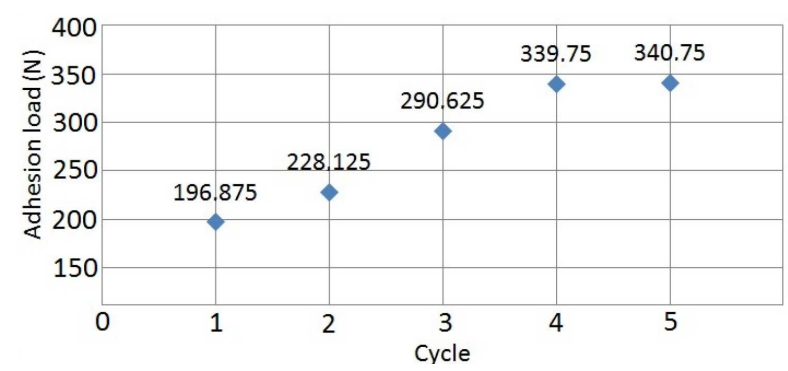

Fig. 3. Adhesion strengths of the coating.
All the XRD peaks of the coating, illustrated in Fig. 2a, matched HAP (JCPDS Card No. 9-432) and no other phase was observed. The FTIR spectrum in Fig. $2 \mathrm{~b}$ is characteristic peaks of HAP. Fig. 3 indicates the bonding strength between the coating and alloy. It was observed that adhesion load increased depending on the number of cycles. It was found that the maximum bonding strength value was $340.75 \mathrm{~N}$ at cycle 5 .

\section{Conclusion}

In this study, HAP coatings were successfully prepared on Ti6Al4V titanium alloy substrates using microwaveassisted immersion method. The influence of coating number of cycle and coating time of cycle on the surface morphology and adhesion load was evaluated. The XRD pattern and FTIR spectrum of the samples show that the coating is consist of HAP. The adhesion load and surface uniformity increased with increasing number of cycles and reached a maximum value, $340.75 \mathrm{~N}$ when the number of cycle was 5 . Microwave assisted immersion technique was found to be a simple and efficient way to coat Ti6Al4V alloys with HAP.

\section{Acknowledgments}

The authors would like to acknowledge the financial supports provided by Bilecik Şeyh Edebali University, Scientific Research Project (BAP), under grant number 2016-01.BŞEÜ.03-05

\section{References}

[1] S. Bose, S.F. Robertson, A. Bandyopadhyay, Acta Biomater. 66, 6 (2018).

[2] D. He, P. Liu, X. Liu, F. Ma, X. Chen, W. Li, J. Du, P. Wang, J. Zhao, J. All. Compd 672, 336, (2016).

[3] H. Zhou, M. Nabiyouni, S.B. Bhaduri, Mater. Sci. Eng. C 33, 435 (2013).

[4] Y. Wang, H. Yu, C. Chen, Z. Zhao, Mater. Des. 85, 640 (2015).

[5] A.L. Nikolaeva, A.V. Gopin, A.V. Severin, V.N. Rudin, M.A. Mironov, N.V. Dezhkunov, Ultrason. Sonochem. 44, 390 (2018).

[6] C. Tas, B.Sarit, J. Mater. Res 19, 2742 (2004).

[7] H. Ye, X. Yang L. H. Hong, Mater. Sci. Eng. C 29 , 2036 (2009).

[8] C.Y. Zheng, S.J. Li, X.J. Tao, Y.L. Hao, R. Yang, L. Zhang, Mater. Sci. Eng. C 27, 824 (2007).

[9] D.H. He, P. Wang, P. Liu, X.K. Liu, F.C. Ma, Surf. Coat. Tech. 301, 6 (2016). 